\title{
Analysis of coatings appearance and durability testing induced surface defects using image capture/processing/analysis
}

\author{
F. Lee*, B. Pourdeyhimi**, C. Hazzard* and J. Summerville*
}

\begin{abstract}
There are no established and accepted techniques available for accurate characterization appearance changes brought about by scratch and mar damage. Scratch and mar resistance is related to the ability of a coating in resisting deformation. The appearance change is brought about by surface roughening which in turn leads to a reduction in gloss and reflectivity. This paper focuses on the measurement of the appearance of coating by image analysis and gloss measurement.
\end{abstract}

Keywords Automotive coatings. Scratch and mar. Scratch resistance. Image analysis. Optical imaging.

\section{Análisis de la apariencia de los recubrimientos y ensayos de durabilidad de defectos inducidos en superficies usando un sistema de análisis de proceso de captación digital de imágenes}

\begin{abstract}
Resumen No hay técnicas establecidas o aceptadas para una caracterización precisa de los cambios de apariencia dados por los rayones profundos y daños superficiales en los recubrimientos. La resistencia a estos eventos está relacionada con la habilidad del recubrimiento a resistir la deformación. El cambio de apariencia se presenta en la superficie como una aspereza que va llevando a la reducción del brillo y de la reflectancia. Este trabajo se centra en las mediciones de apariencia de un recubrimiento por análisis de imágenes y medición de brillo.
\end{abstract}

Palabras clave Recubrimientos automotrices. Rayones profundos y daños superficiales. Resistencia al rayado. Análisis de imagen. Imagen óptica.

\section{INTRODUCTION}

Materials durability studies of coatings involve precise monitoring and meaningful analysis of the coating's appearance and surface defects ${ }^{[1-6}$ and $\left.8-11\right]$. The current techniques that monitor and analyze coatings are oftentimes deficient in accurate characterization of the coating's appearance. Unfortunately, appearance measurement is an assessment of the human visual attributes of an object. Unlike other material properties, the appearance properties are tied to human psychology. As with other subjective visual assessments, the results are often sensitive to biases in an individual's perception. Recommended protocol often requires the estimation of size, shape and distribution characteristics by eye-perceptual judgments that are often tedious and timeconsuming. The complex response of human perception can be, however, partially measured using photometric devices. While photometric devices can measure the amount of light reflected from the target area of an object, the spatial composition of the target area is still at a loss. Hence it would be desirable to develop automated instrumental methods such as digital imaging, incorporating two-dimensional imagery for evaluating coating integrity and measuring degradation.

This article describes: 1) shortfalls of the conventional photometric appearance measurement techniques in weathering and durability applications, 2) an overview of a digital image capture/processing/analysis system, 3) the applicability of the

(*) Atlas Electric Devices Company, Chicago, IL., U.S.A.

$(* *)$ School of Textiles, North Carolina State University, Raleigh, NC, USA 
digital image capture/processing/analysis technology for automotive coatings durability studies, specifically in the visualization and the quantitative analysis of automotive topcoat defects such as scratch and mar defects, acid etch defects.

\section{IMAGE CAPTURE/IMAGE PROCESSING/ANALYSIS SYSTEM - HARDWARE}

A typical imaging system is comprised of largely two separate functional components. These are: 1) The optical component (Image acquisition) and 2) The computing component (Image processing/analysis). The optical component is comprised of illumination sources and focusing optics.

The importance of light geometry cannot be overstated in photometric devices. For an imaging system, it is impossible to use conventional lighting schemes commonly used with commercial image capture and other photometric systems. Unlike the conventional photometric devices where a two dimensional optical arrangement is usually adequate, an imaging system requires a three dimensional optical arrangement where the focal plane is perpendicular to the optical axis in order to provide spatially even focusing.

It is well known that it is most discriminating (as far as reflectance or gloss is concerned) when light is directed to a surface at a low incident angle. The most ideal incident angle is $0^{\circ}$. This angle is particularly useful for capturing surface texture and roughness. When the light is directed to surface at $0^{\circ}$ angle, it will be reflected from the surface at $0^{\circ}$. When a stream of light is reflected perpendicularly $\left(0^{\circ}\right)$ from the surface, the direction of reflection is confined to $0^{\circ}$ if the surface is optically smooth. However, when the surface is not optically smooth, the light will be reflected from the surface at angles greater than $0^{\circ}$ (see figure 1).

This scattering effect of reflected light is most beneficial in examining surfaces in the presence of dirt, scratches, and streaks (common in weathered surfaces). These characteristics render conventional gloss measurements unreliable. When the light is reflected at large angles caused by the irregularity of the surface the scattering would not affect image formation since it is not detected by the target receptor. Figure 2 is a composite of four automotive top coat images captured using the $0^{\circ}$ incident angle system showing the off-axis scattering of scratch marks appearing as dark lines.

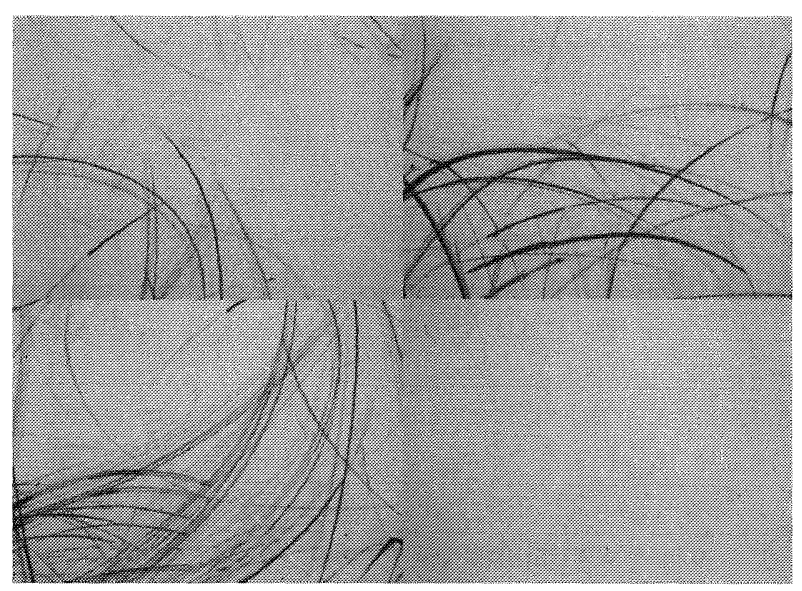

Figure 2. The scattering effect of $0^{\circ}$ incident reflected light.

Figura 2. El efecto de dispersión de la luz reflejada incidente $a 0^{\circ}$.

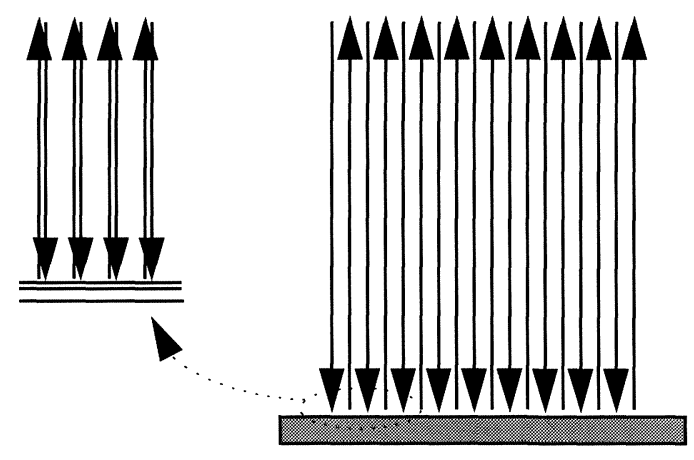

Optically Smooth Surface

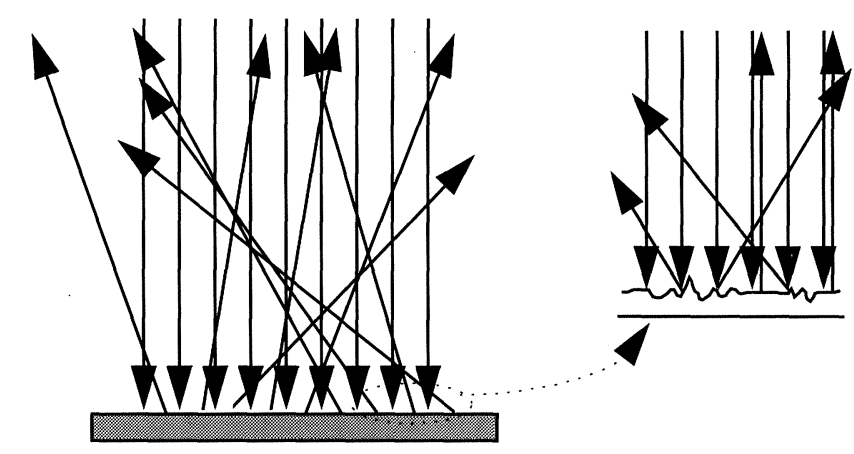

Optically Rough Surface

Figure 1. The $0^{\circ}$ incident light interaction.

Figura 1. Interacción de la luz incidente a $0^{\circ}$. 


\section{IMAGE CAPTURE/IMAGE PROCESSING/ANALYSIS SYSTEM - SOFTWARE}

The image analysis software deals with specific defect types. In dealing with each defect, the program needs to decide what attributes are relevant and how they can best be measured. Some deal with the estimation of size, shape and distribution characteristics while others derive first order as well as second order surface texture properties to estimate damage. The first category, by its nature, requires a binary image as input, thus requiring a thresholding step to convert the image to black and white. The thresholding method selected must be appropriate for the defects in question. The measurements made for each are described separately below when discussing each application.

\section{APPLICATIONS - COATINGS APPEARANCE MEASUREMENT - SCRATCH AND MAR DEFECTS}

Scratch and mar resistance testing of automotive coatings is done routinely and used as the basis for comparison of a coating's mechanical performance. Traditionally, both (lubricated) wet and dry mar testing protocols have been used ${ }^{[11]}$ to inflict scratch and mar damage similar to that encountered in the field. Wet mar, for example, occurs in car washing, which is generally considered the most significant contributor to this type of damage, and in buffing operations used during repair. Dry mar comes from a broad range of materials that can contact the coating such as clothing, keys, paper, building materials, blowing sand, bushes, etc. Various imaging techniques, including optical and atomic force microscopy, have been used to determine type and extent of damage.

The materials used for this scratch and mar application are high-solid BC/CC coating systems. All panels have three coats of paint on the same metallic substrate primer, basecoat (colorcoat), and clearcoat. The clearcoat is the topcoat. For all paint panels, the basecoat (colorcoat) was black. The panels measured $10.1 \mathrm{~cm} \times 31.5 \mathrm{~cm}$. The materials chosen in this study comprised three clearcoat systems. The first sample is an acrylic polyol - melamine-formaldehyde (MF)- crosslinked clearcoat, the second is an acrylic acid - epoxycrosslinked clearcoat and the third sample is an acrylic polyol - isocyanate-crosslinked clearcoat. For simplicity, these will be referred to as Melamine,
Epoxy and Polyurethane respectively. The Crockmeter Mar Test is a widely used laboratory test method from the standpoint of repeatability. For our work, a computer-controlled Crockmeter Test Instrument was designed and developed. The equipment is similar to a crockmeter, but has several advantages over conventional crockmeters. In the crockmeter, a weighted arm is moved back and forth at precise predetermined speeds. The number of scratch cycles, the scratch normal load, the abrasive media and scratch translation rate are adjustable.

This study focuses on dry abrasion only. The abrasion medium was a fresh (unused) "ultra-fine" grade Scotch-Brite ${ }^{\mathrm{TM}}$ (3 M company). Each test paint panel was clamped on the stage, and a test probe covered with a fresh "ultra-fine" grade Scotch-Brite ${ }^{\mathrm{TM}}$ was moved back and forth several times over a portion of the panel. Next, the panel was cleaned with copious quantities of warm tap water to remove loose debris arising from abrasion and gently dried with soft paper towel. Scratch clusters in the order of increasing scratch cycles or increasing scratch loads could be made on a single paint panel.

The test panels were conditioned for at least $48 \mathrm{~h}$ at $23 \pm 2{ }^{\circ} \mathrm{C}\left(73.5 \pm 3.5^{\circ} \mathrm{F}\right)$ and $50 \pm 5 \%$ relative humidity, and tested in the same environment.

For all samples, two series of experiments were prepared as shown in table I. The first experiment was designed to examine the extent of damage with increasing scratch cycles, and the second experiment was designed to examine the extent of damage with increasing scratch loads.

All samples were imaged with a digital imaging system developed at Atlas Electric Devices Company. For each condition, five images were obtained. The gloss values for panels were also determined by using a BYK glossmeter.

\section{IMAGE ANALYSIS METHODS}

\subsection{Moments}

There are a number of methods available for characterizing surface features. It is clear that an increase in scratch and mar will be reflected in a lower reflectivity. This is true for the system used since the light source is calibrated and maintained in an enclosure to remove interference from external (ambient) conditions. Therefore, first order measurements from the image histogram 
Table I. Scratching and marring conditions

Tabla I. Condiciones de rayado profundo y rayado superficial

\begin{tabular}{|c|c|c|c|c|c|}
\hline Experiment & $\begin{array}{l}\text { Scratch Translation } \\
\text { Load (um/s) }\end{array}$ & Scratch Medium & $\begin{array}{l}\text { Scratch Length } \\
(\mathrm{mm})\end{array}$ & $\begin{array}{l}\text { Scratch Load } \\
\text { (g) }\end{array}$ & $\begin{array}{l}\text { Scratch Cycles* } \\
\text { (N) }\end{array}$ \\
\hline 1 & 3 & $\begin{array}{l}\text { "Ultra fine" Grade ScotchBrite } \\
\text { (Diameter: } 25 \mathrm{~mm} \text { ) }\end{array}$ & 80 & 240 & $1,2,4,6,8$ \\
\hline 2 & 3 & $\begin{array}{l}\text { "Ultra fine" Grade ScotchBrite } \\
\text { (Diameter: } 25 \mathrm{~mm} \text { ) }\end{array}$ & 80 & $87,240,392,545,677$ & 4 \\
\hline
\end{tabular}

* Each cycle represents a complete traverse.

such as mean and variance can provide both absolute as well as relative measures of marring.

We begin by examining the mean $(x)$ and standard deviation $(s)$ of image intensities. Elementary probability suggests that an image generated by randomly sampling a discrete uniform distribution, $U\left(G_{\min }, G_{\max }\right)$ has an expected intensity value of $\left(G_{\min }+G_{\max }\right) / 2$ and a variance of $\left[\left(G_{\max }-G_{\min }+1\right)^{2}-1\right] / 12$. Most 'natural' images have a distribution that approaches normality, although often exhibiting a distinct skew.

Gregorovich and coworkers ${ }^{[11]}$ concluded that appearance change was mainly due to an increase in overall reflectance. Note that our expectation is the opposite. That is, appearance change arises from loss of gloss and lowered reflectivity. Since there is a limit to the degree of surface roughening, the reflectivity curve should resemble a saturation curve when plotted against the amount of wear. This implies that at very high levels of wear, the sensitivity with which reflectivity can be determined is reduced.

A gray level ( 8 bits per pixel) image with dimensions $N \times N$ pixels may be considered as a collection of $N^{2}$ points of surface data having the statistical moments of mean, variance, skew, kurtosis and so on. Each image was sequentially scanned and the appropriate moments were computed according to conventional formulae. Note, however, that an image is not composed of $\mathrm{N}^{2}$ random samples; rather, an image should be construed as a single sample. Thus standard errors of statistics computed for a given image are not relevant for our purposes, and are not reported here. Results for the statistics examined in this paper are plotted for the mean and standard errors obtained from five separate images without any overlapping regions.

\subsection{Texture roughness}

Texture roughness refers to the overall degree of surface roughness. The clearcoat is initially smooth, but roughens with wear. The extent to which the surface roughens is a robust measure of the potential to scratch and mar.

Profileometry is typically performed using dedicated equipment for measuring surface roughness and features. Here, we use image scan lines much the same way. The height and the degree of distortion of a surface from a plane can be characterized using the Power spectral Density of a function $c_{t}$ of profile by taking the modularsquared of the discrete Fourier transform of some finite, sampled stretch of it. In general, there is some relation of proportionality between a measure of the squared amplitude of the function and a measure of the amplitude of the PSD.

The method of PDS estimation is a simple version of an estimator called historically, the periodogram. If we take an $\mathrm{N}$-point sample of the function $c_{t}$ at equal intervals and compute its discrete Fourier transform

$$
\mathrm{C}_{k}=\sum_{f=0}^{N-1} c_{f} e^{2 i j \pi / N} \quad k=0, \ldots, N-1
$$

then, the periodogram estimate of the power spectrum is defined as $N / 2+1$ frequencies as:

$$
\begin{aligned}
& P(0)=P\left(f_{0}\right)=\frac{1}{N^{2}}\left|C_{0}\right|^{2} \\
& P\left(f_{k}\right)=\frac{1}{N^{2}}\left[\left|C_{k}\right|^{2}+\left|C_{N-k}\right|^{2}\right] ; \quad k=1,2, \ldots,(N / 2-1) \\
& P\left(f_{c}\right)=P\left(f_{N / 2}\right)=\frac{1}{N^{2}}\left|C_{N / 2}\right|^{2}
\end{aligned}
$$

where, $f_{k}$ is defined for zero and positive frequencies ${ }^{[12]}$. 
Analysis of coatings appearance and durability testing induced surface defects using image capture/processing/analysis F. LEe, B. Pourdeyhimi, C. Hazzard and J. SummerVille

PSD provides information on "how much power" is contained in the frequency interval between $f$ and $f+{ }_{d} f$. The area under PSD function will be a representative index of it. A smooth surface (unscratched surface) will be expected to have low power; the power will increase with increasing roughness (scratching).

\section{RESULTS AND DISCUSSION}

Images for all three samples are shown in figures 3 and 4. Note that the samples become damaged easily after 8 cycles (16 traverses). This is due to the fact that the pad used is fairly harsh. This pad was intentionally chosen so as to accelerate the scratching behavior and minimize the number of samples required. It may be seen clearly that the Polyurethane specimen shows the greatest loss of reflectivity followed by the Epoxy and the Melamine samples. This is in agreement with the results obtained from nanoscratching experiments.

As indicated earlier, with increasing marring and scratching, the image becomes darker. The decrease in intensity is accompanied by an increase in the variance of the intensities.

The intensity (reflectivity) of the samples can be normalized to that of the control to derive \% reflectivity. This will be a similar measure to gloss retention. \% Reflectivity results as a function of the number of scratch cycles and scratch load are given in figures 5 and 6 . It is clear that the same trends are maintained. The Melamine retains a higher degree of reflectivity than its two other counterparts. The Polyurethane shows the highest degree of loss.

All data for scratch cycles and scratch loads are plotted against gloss retention in figures 7 and 8 . It is evident that there is a perfect correlation between the gloss measurement and our \% reflectivity. As indicated earlier, the gloss measurement can be influenced by the basecoat chromatic properties. The basecoat was the same for all the samples used in this study. Our \% reflectivity is best described as $0^{\circ}$-gloss retention.

Figure 9 shows the texture roughness results for the three sets. Notice that the same trend is observed. The Polyurethane appears to roughen more readily than the others do. At high levels of wear however, the image becomes too dark and lacks features making texture measurements difficult and unreliable. Texture roughness is a robust measure of appearance and quite discriminating at the early stages of wear, but should not be used when the images are too dark and lack features.

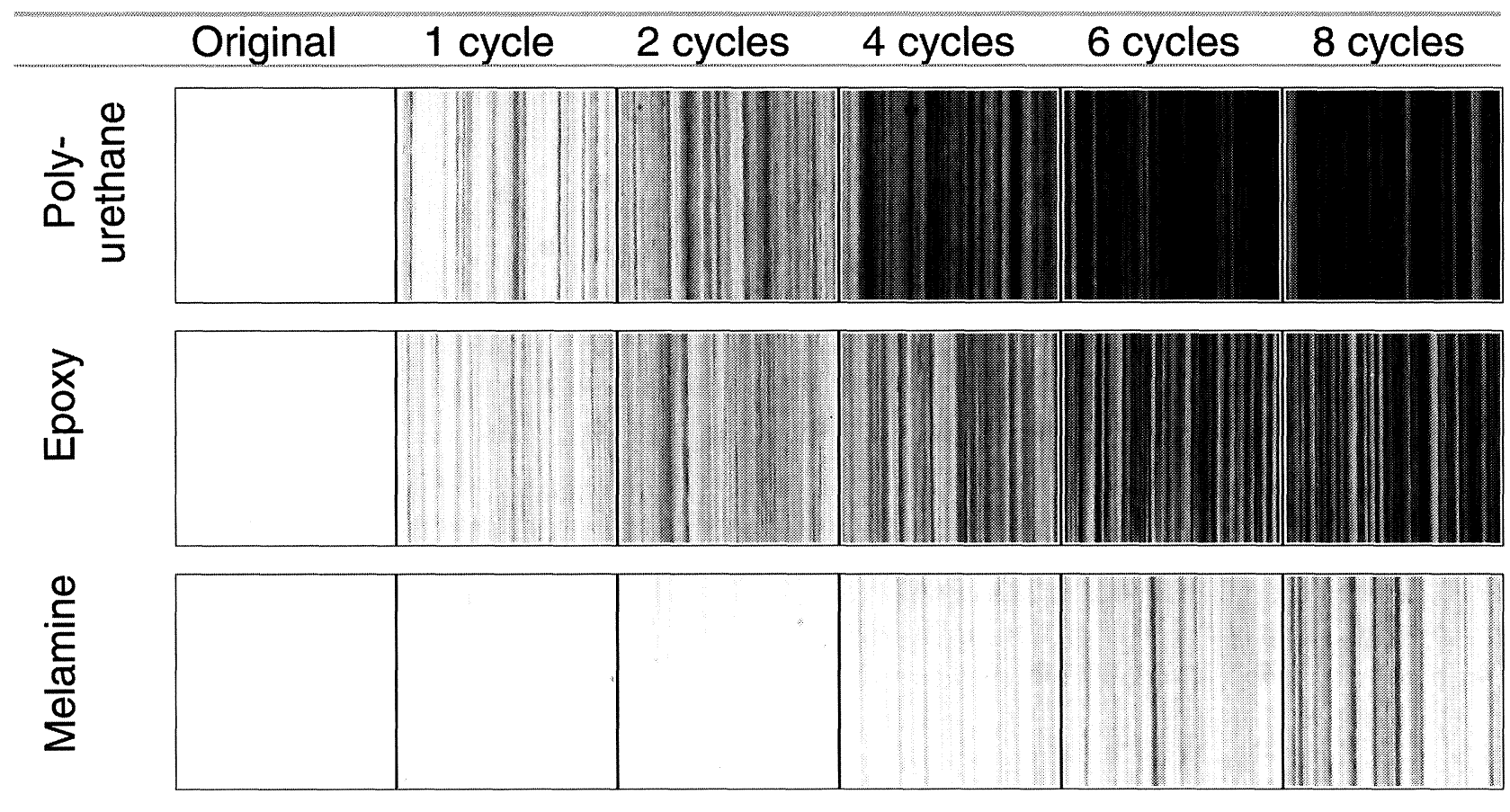

Figure 3. The effect of scratch cycles at $240 \mathrm{~g}$ load.

Figura 3. Efecto de ciclos de rayado profundo a $240 \mathrm{~g}$ de carga. 


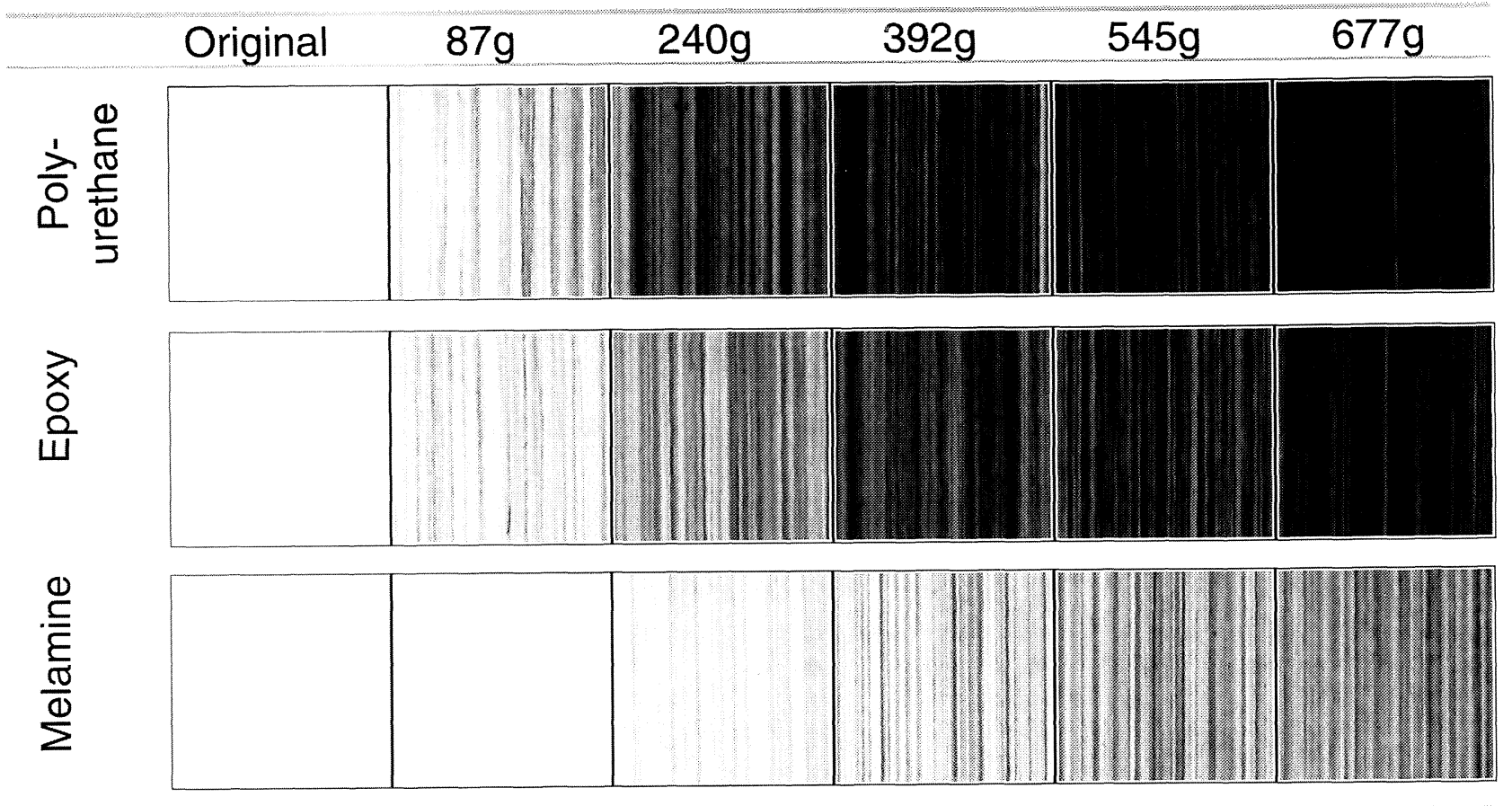

Figure 4. The effect of scratch load at 4 cycles.

Figura 4. El efecto de la carga de rayado profundo a 4 ciclos.

\section{CONCLUSION}

Understanding surface deterioration is an important factor in durability and weathering studies. Quantitative understanding of surface change is fundamental to better relate various external factors resulting in coatings degradation. Meaningful visualization also aids researchers to observe the onset of surface change to further their efforts to understand kinetics of chemical, physical and

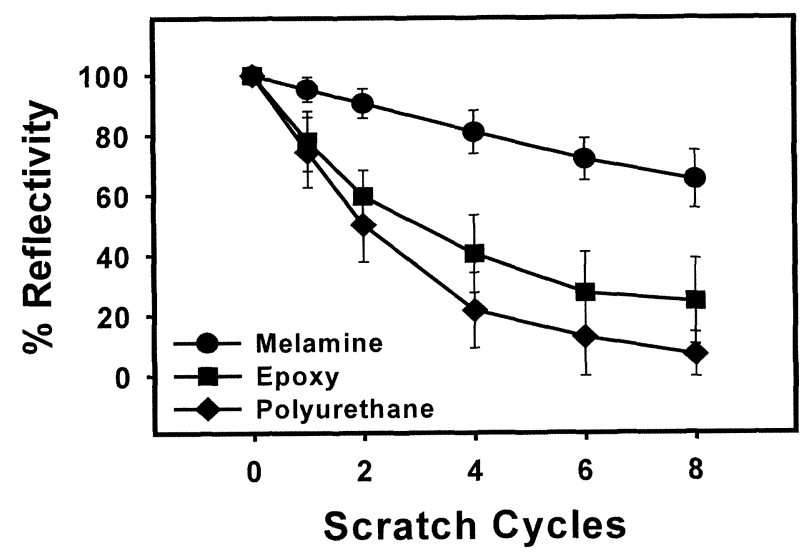

Figure 5. Optical reflectivity as a function of scratch cycles.

Figura 5. Reflectividad óptica como una función de los ciclos de rayado profundo. mechanical degradation. In this report, several automotive coating defects were analyzed using an imaging/image processing/analysis system. The imaging/image processing/analysis system provided precise and useful surface information. It was also shown that the imaging data was closely conformant to conventional evaluation techniques. The information obtained via the imaging system would also be directly beneficial to formulate a meaningful service life prediction.

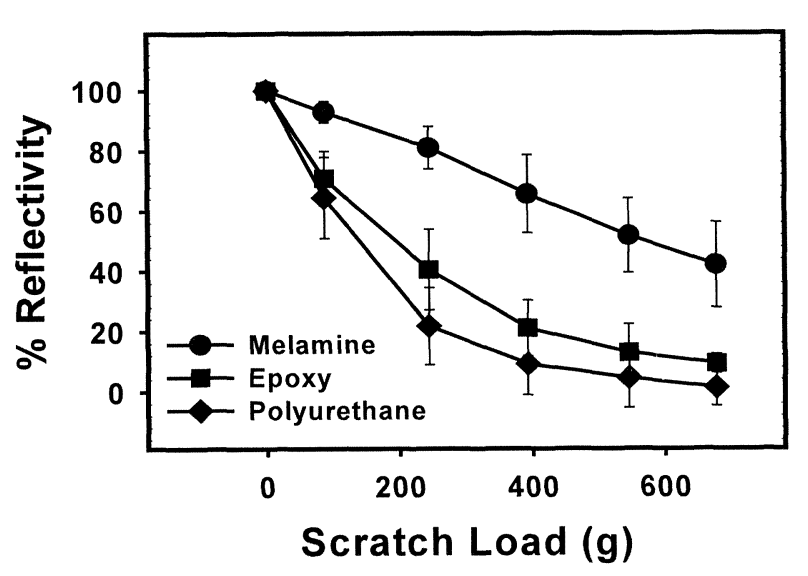

Figure 6. Optical reflectivity as a function of load.

Figura 6. Reflectividad óptica como función de la carga. 


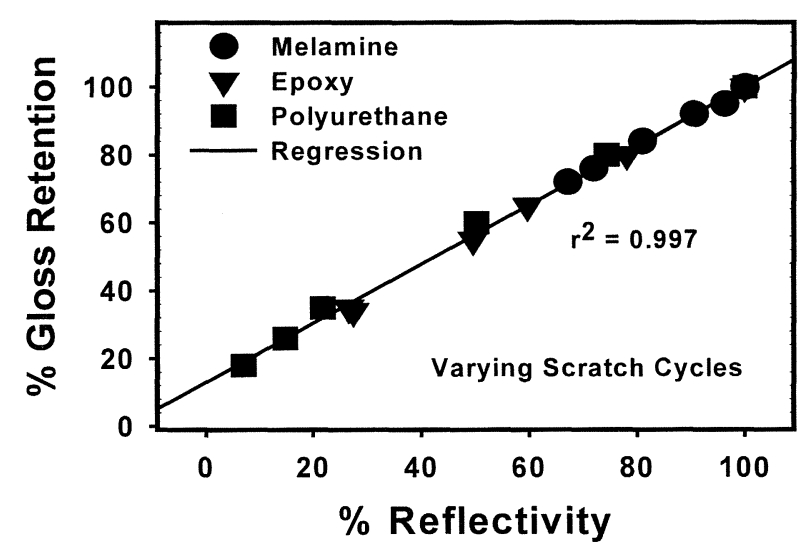

Figure 7. Optical reflectivity at varying scratch cycles versus gloss retention.

Figura 7. Reflectividad óptica a ciclos variables de rayado profundo versus retención de brillo.

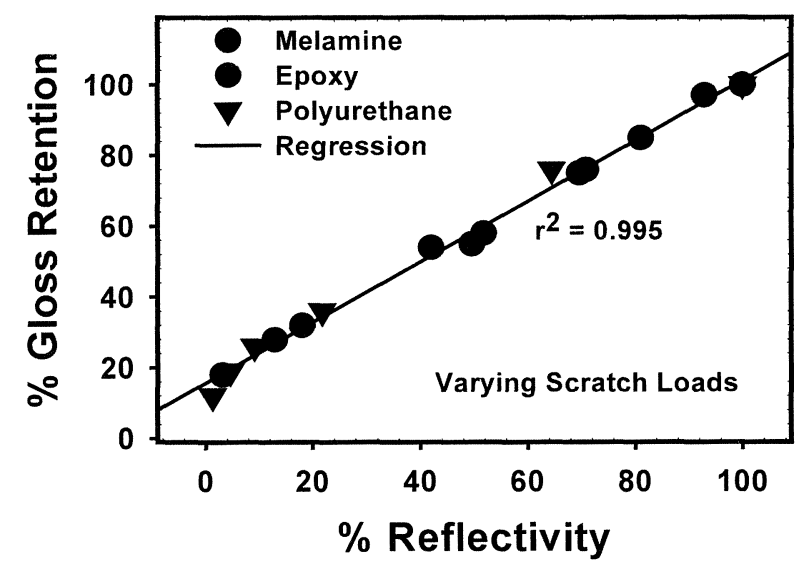

Figure 8. Optical reflectivity at varying scratch loads versus gloss retention.

Figura 8. Reflectividad óptica a cargas variables de rayado profundo versus retención de brillo.

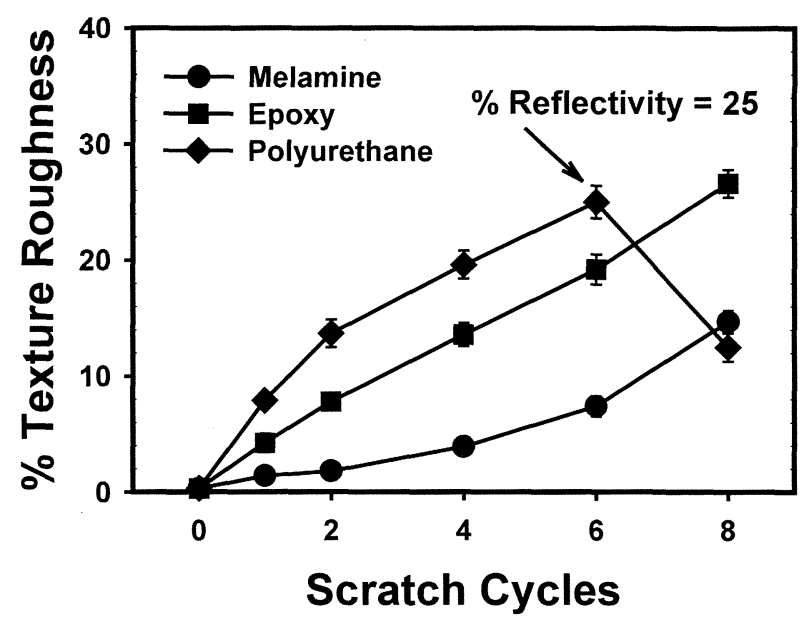

Figure 9. Texture roughness as a function of scratch cycles, at $240 \mathrm{~g}$ load.

Figura 9. Asperezas de la textura en función de los ciclos de rayado profundo a una carga de $240 \mathrm{~g}$.

\section{REFERENCES}

[1] R.A. Dickie, J. Coat. Tech. 6\6 (834) (1994) 29.

[2] D.R. BAuer, J. Coat. Tech. 66 (835) (1994) 57.

[3] D.R. Bauer, Prog. Org. Coat. 1986 (14) (1994) 193.

[4] R.A. Dickie, J. Coat. Tech. 64 (809) (1992) 61.

[5] J.L. Gerlock, C.A. Smith, E.M. Nunez, V.A. COOPER, P. Liscombe and D.R. Cummings, Proc. 36-th, Annual Technical Symposium, Cleveland, OH., May, 1993, p. 14.

[6] J.L. COURTER, 23-rd Annual International Waterborne, HighSolids and Powder Coatings Symposium, New Orleans, LA., Feb. 1996, pp. 14-16.

[7] K. Leithner, Adv. Mater. \& Proc. 11 (1993) 18.

[8] G. Dubbeldam, Prog. Org. Coat. 20 (1992) 261.

[9] R. Kody and D. Martin, Polymer Eng. Sci. 36 (1996) 2.

[10] R. Quazi, S. Bhattacharya, E. Kosior and R. Shanks, Surf. Coat. Int. 2 (1996) 63.

[11] L.W. Hill, H.M. Korzeniowski, M. OJunga-Andrew and R.C. Wilson, Prog. Org. Coat. 24 (1994) 147.

[12] W.H. Press, B.P. Flannery, S.A. TeukOlsky and W.T. Vetterling, Numerical Recipes in C; The Art of Scientific Computing, Cambridge University Press, Cambridge, 1988. 